\title{
Pengaruh Kepribadian dan Budaya Organisasi Terhadap Kepemimpinan dan Organizational Citizenship Behavior Pada Dosen UIN Suska Riau
}

\author{
Dody Leyno Amperawan'1, Susi Hendriani², Marzolina ${ }^{3}$ \\ ${ }^{1}$ Fakultas Psikologi UIN Suska Riau \\ ${ }^{2,3}$ Fakultas Ekonomi dan Bisnis Universitas Riau \\ email: pulaupisang67@yahoo.com
}

\begin{abstract}
Abstrak
Keberadaan dosen merupakan salah satu faktor penting dalam kemajuan suatu organisasi perguruan tinggi melalui kontribusi pelaksanaan tugas pokok tri dharma perguruan tinggi. Penelitian ini bertujuan untuk menguji pengaruh kepribadian dan budaya organisasi terhadap kepemimpinan. Serta untuk melihat pengaruh kepemimpinan terhadap Organizational Citizenship Behavior Penelitian ini dilakukan pada 107 orang dosen Universitas Islam Negeri Sultan Syarif Kasim Riau yang telah mengisi empat skala penelitian yaitu skala Kepribadian, skala Budaya Organisasi, skala Kepemimpinan, dan skala Organizational Citizenship Behavior. Analisa data dilakukan dengan menggunakan analisis regresi berganda dan analisis regresi sederhana, melalui program SPSS Versi 20.00 for Windows. Hasil penelitian menunjukkan bahwa ada pengaruh yang signifikan antara kepribadian dan budaya organisasi terhadap kepemimpinan. serta ada pengaruh yang signifikan antara kepemimpinan terhadap Organizational Citizenship Behavior.
\end{abstract}

Kata Kunci: kepribadian, budaya organisasi, kepemimpinan, dan organizational citizenship behavior

\section{The Influence of Personality and Cultural Organization on Leadership and Organizational Citizenship Behavior on Lecturer at UIN Suska Riau}

\begin{abstract}
The existence of a lecturer was one important factor in the progress of a college organization through lecturer's main tasks contribution which named college tri dharma. This study aims to examine the influence of personality and organizational culture on leadership. As well as to see the effect of leadership on Organizational Citizenship Behavior This study was conducted on 107 people lecturer at State Islamic University Syarif Kasim Sultan who filled four scales research which are personality scale, the scale of Organizational Culture, Leadership scale, and the scale of Organizational Citizenship Behavior. Data was analyzed by multiple regression and simple regression analysis, by SPSS for Windows Version 20.00. The results showed that there was a significant relationship between personality and organizational culture on leadership, and there was a significant relationship between leadership and Organizational Citizenship Behavior.
\end{abstract}

Keywords: personality, organizational culture, leadership, and organizational citizenship behavior

\section{Pendahuluan}

Dosen menempati posisi penting yang sangat berarti dalam kegiatan operasional suatu perguruan tinggi karena dosen terlibat langsung dengan organisasi perguruan tinggi tempat ia bekerja. Dosen merupakan salah satu faktor yang memiliki peran penting dalam memberikan kontribusi terhadap pencapaian visi, misi dan tujuan suatu perguruan tinggi. Dosen merupakan sumber pengetahuan, keterampilan dan kemampuan keahlian yang terakumulasi dalam diri anggota organisasi perguruan tinggi. Sehingga dosen merupakan sumber daya perguruan tinggi yang harus dikelola dan selalu dikembangkan terus menerus (diakses dari www.jakartaconsulting. com/extra_corner_archive12.shtml, Mei 2006, diakses tangal 12 Desember 2013).

Demikian juga halnya dengan keberadaan dosen di UIN Suska Riau, dosen memiliki fungsi sebagai image builder (pembangun citra) yang menghubungkan perguruan tinggi dengan publik (mahasiswa, kar- 
yawan, orang tua atau wali, para profesional dan sebagainya) melalui pelaksanaan tugas pokok tridharma perguruan tinggi. Oleh karena itu dosen dituntut untuk lebih proaktif dan responsif menanggapi lalu meluruskan berbagai permasalahan atau isu aktual yang tengah berkembang dimasyarakat dan bersentuhan langsung dengan pelaksanaan kebijakan perguruna tinggi, sehingga tidak terjadi distorsi informasi dan komunikasi di masyarakat. Hal ini dimaksudkan agar masyarakat dapat memahami dengan benar dan akurat terhadap berbagai kebijakan maupun produk hukum yang dihasilkan perguruan tinggi.

Meskipun demikian, temuan penelitian menunjukkan dosen masih memiliki kinerja rendah karena kurang mencurahkan perhatian pada profesinya dengan datang tidak tepat waktu (Jani, 2009), belum optimal dalam mengajar, membimbing akademik dan penyusunan skripsi karena profesi dosen bukanlah pilihan utama sehingga kurang memiliki motivasi kerja, sepertimengajar tidak sesuai dengan jumlah SKS (Satuan Kredit Semester) dan RPP (Rancangan Pokok Pengajaran),belum memanfaatkan media pembelajaran secara optimal, dan belum menerapkan model-model pembelajaran yang dapat mengaktifkan mahasiswa dalam proses belajar mengajar (Iskandar, 2011). Hasil penelitian Ilyassin (2010) menemukan permasalahan bahwa dosen masih kurang memiliki komunikasi yang baik dengan unsur pimpinan, kesenjangan komunikasi antara pimpinan dan dosen, dosen dan pegawai, belum terdapat kesamaan visi dalam mengembangkan lembaga, menggunakan pola-pola pembelajaran konvensional, dan masih menunggu perintah daripadaberinisiatif dalam mengerjakan tugas profesi sebagai dosen.

Hasil observasi terhadap permasalahan kinerja dosen juga terdapat di Universitas Islam Negeri Sultan Syarif Kasim Riau, seperti masih terdapat dosen yang belum memaksimalkan penggunaan metode mengajar berbasis SCL (Student Centered Learning), belum mengintegrasikan softskill, dan belum menggunakan media pembelajaran secara optimal. Selain itu masih terdapat dosen yang melaksanakan tugas tidak tepat waktu, merubah jadwal tanpa berkomunikasi dengan bagian akademik sebagai penanggungjawab dan konflik internal dalam team teaching. Selain itu dosen juga kurang memberikan umpan balik pada mahasiswa mengenai hasil pembelajaran (misalnya dengan mengembalikan tugas atau lembar jawaban ujian mahasiswa yang telah diperiksa).

Jika memperhatikan makna tridharma perguruan tinggi tentang peranan dosen yang sangat strategis bagi kemajuan sebuah perguruan tinggi, maka peran dosen sangat menentukan mutu pendidikan dan lulusan per- guruan tinggi. Peran dosen pada dasarnya sangat kompleks, tidak hanya mencakup kegiatan rutin mengajar, meneliti dan melakukan kegiatan pengabdian masyarakat 2 (dua) sks dalam setahun saja tapi lebih dari itu. Kenyataan ini didukung oleh pendapat Tampubolon (2001:8) bahwa peran dosen bersifat multidimensional dan bergradasi menurut jenjang pendidikan. Peran strategis yang kompleks tersebut adalah sebagai: orang tua melalui tugas sebagai pembimbing akademik, pendidik melalui tugas sebagai pengontrol perilaku agar sesuai norma etika, pengajar melalui tugas sebagai narasumber materi kuliah di dalam kelas, pemimpin atau manajer melalui tugas pengarahan dan mempengaruhi mahasiswa agar melakukan tugas sesuai kewajibannya, produsen atau pelayan melalui tugas menyiapkan dan menyajikan materi kuliah sesuai kebutuhan ideal, pembimbing dan fasilitator bagi mahasiswa dalam proses menyelesaikan tugas akademiknya, motivator dan stimulator bagi mahasiswa dan pegawai agar selalu giat bersemangat menyelesaikan tugas - tugas di kampus, serta peneliti dan narasumber dalam kegiatan pengabdian masyarakat.

Dosen sebagai sumber daya manusia yang bergerak pada bidang pendidikan dan pengajaran di Perguruan Tinggi diharapkan tidak hanya bekerja dengan orientasi pada pencapaian produktivitas silabus pengajaran untuk memenuhi kewajiban kerjanya saja, akan tetapi mampu menunjukkan kinerja unggulyang memiliki kontribusi lebih melalui munculnya perilaku kerja di atas rata-rata melebihi tuntutan formal organisasi, namun disisi lain juga tidak menuntut penghargaan formal. Hal ini patut diperhatikan karena dosen memiliki peranan penting sebagai ujung tombak Perguruan Tinggi yang menjadi role model bagi mahasiswa, karyawan, maupun masyarakat pengguna jasa Perguruan Tinggi.

Perwakilan mahasiswa dalam acara dialog antar lembaga kemahasiswaan dengan Rektor UIN Suska Riau menyampaikan bahwa masih ada dosen yang kurang terampil dan asal-asalan dalam mengajar, keluhan lain adalah mereka tidak mendapatkan pengetahuan yang sesuai dengan tujuan mata kuliah seringkali tidak mendapat tanggapan yang memuaskan. Kegiatan membimbing mahasiswa juga masih ada yang dilaksanakan kurang serius, sehingga cukup banyak mahasiswa tidak mendapat informasi sesuai dengan kebutuhannya. Metode mengajar yang membosankan, materi kuliah yang tidak diperbaharui, sikap dosen yang pasif dan kurang peduli dengan lingkungan merupakan hal yang sering kali menjadi keluhan bagi kebanyakan mahasiswa (http://www.goriau. com/berita/ pendidikan/ini-harapan-mahasiswa-uin-Suska-riau-untuk-prof-munzir hitami.). 
Perilaku sukarela yang melebihi tuntutan formal tanpa mengharapkan penghargaan formal dari organisasi di dalam teori organisasi dikenal dengan organizational citizenship behavior (OCB). OCB berkaitan dengan kualitas kinerja dosen pada saat ia melaksanakan tugas pengajaran, mulai dari mempersiapkan bahan materi pengajaran, memperbaharui bahan materi pengajaran, merencanakan metode pengajaran dan media pembelajaran, memberikan nilai tugas dan ujian kepada mahasiswa, selalu menjaga penampilan yang menarik dan tidak membosankan bagi mahasiswa dan rekan kerja lainnya sampai dengan melaksanakan seluruh tugas tri dharma perguruan tinggi. Seluruh aktivitas tersebut dilakukan atas inisiatif dan kepemimpinan dari diri dosen bersangkutan. Organizational Citizenship Behavior adalah perilaku individu berupa kebebasan untuk menentukan atau memilih secara tidak langsung untuk melakukannya dan perilaku tersebut diakui oleh sistem reward secara eksplisit sebagai usaha untuk memajukan fungsi organisasi secara efisien dan efektif. Perilaku ini dapat dilakukan maupun tidak dilakukan individu serta tidak memiliki punishment bagi yang tidak melakukannya (Organ, Podsakoff, \& Mackenzie, 2006: 8).

Organizational Citizenship Behavior adalah keinginan atau perasaan individu untuk melibatkan diri dalam bentuk perilaku yang diinginkan untuk dirinya sebagai karyawan, untuk orang lain dan organisasi berdasarkan alasan pribadinya seperti lebih meningkatkan harga diri, lebih didengar oleh orang lain, dan lebih berkontribusi bagi organisasi (Organ, Podsakoff, \& Mackenzie, 2006: 94 - 95).

Kotter dan Haskett (1997) mengatakan bahwa perilaku kerja ditentukan oleh budaya organisasi dan kepemimpinan yang dikembangkan organisasi, demikian juga dengan keberhasilan perguruan tinggi mempertahankan kinerja SDM nya tidak dapat lepas dari kepemimpinan dan budaya organisasi yang dikembangkan di perguruan tinggi tersebut. Pendapat ini didukung juga oleh Thoyib (2005) yang mengatakan bahwa kinerja karyawan ditentukan oleh kepemimpinan dan budaya organisasi.

OCB akan menjadi pertimbangan dalam penilaian kinerja karena rendahnya kualitas dosen akan menimbulkan dampak negatif bagi organisasi UIN Suska Riau maupun dosen itu sendiri. UIN SUSKA Riau dapat memilih dan mempertahankan dosen yang berkualitas baik dengan mempertimbangkan OCB dosen tersebut. Dosen dengan kinerja baik yang menguntungkan bagi organisasi dapat dilihat dari kecenderungan yang menunjukkan OCB (Organizational Citizenship Behavior) dalam aktivitas sehari - harinya. OCB individu memiliki kontribusi positif ter- hadap organisasi yaitu perilaku kerja yang melebihi tuntutan peran di tempat kerja (Somech \& Zahavy, 2004). Dosen yang memiliki OCB akan dapat mengendalikan perilakunya sendiri sehingga dapat memilih perilaku terbaik untuk kepentingan UIN SUSKA Riau.

OCB merupakan bentuk kegiatan sukarela dari angggota organisasiyang mendukung fungsi organisasi sehingga perilaku ini dapat diekspresikan dalam bentuk tindakan-tindakan yang menunjukkansikap tidak mementingkan diri sendiri dan perhatian pada kesejahteraan orang lain (Elfina, 2003). Jika dosen UIN SUSKA Riau memiliki OCB yang menunjang pencapaian visi dan misi organisasi, maka dosen tersebut dapatmengendalikan perilakunya sendiri sehingga menunjukkan perilaku terbaikyang menunjang pencapaian kepentingan organisasinya. Hasil penelitian Stefhani (2013) juga menunjukkan bahwa OCB memberikan pengaruh secara simultan dan signifikan terhadap kepuasan kerja dan retensi karyawan di organisasi pekerjaan mereka.

Sisi lain yang diduga memiliki kaitan yang sangat erat dengan OCB khususnya perilaku kerja bagi para dosen adalah kepribadian. Teori kepribadian memandang perilaku seseorang dari berbagai sudut pandang. Kepribadian adalah hasil sejumlah kekuatan yang secara bersama membantu membentuk individu unik dan merupakan produk bawaan atau nature sekaligus lingkungan atau nurture (Ivancevich, Konopaske, \& Matteson, 2007: 92 - 93). Kepribadian adalah jumlah total cara individu bereaksi dan berinteraksi dengan lainnya. Kepribadian adalah hasil pembentukan dari faktor lingkungan, keturunan, dan situasi (Robbins, 2006: 126). Teori Lima Dimensi Kepribadian atau The Big Five Personality mengulas kepribadian dari beberapa dimensi sebagaiakumulasi praktek kerja yang mencerminkan pengalaman, keyakinan, sosialisasi, dan kecerdasan emosi seseorang. Debora dan Ali (2004) yang menunjukkan adanya kontribusi positif kepribadian terhadap OCB.

Selain itu, penelitian yang dilakukan oleh Hardaningtyas (2004) juga menunjukkan budaya organisasi berpengaruh signifikan terhadap OCB. Hal ini dapat diartikan bahwa budaya organisasi adalah adanya kebersamaan para anggota organisasi untuk berperilaku sama, baik diluar maupun dalam organisasi dengan menggunakan ciri-ciri khas, berperilaku sama, berbeda dari organisasi lain dan diajarkan dari generasi ke generasi berikutnya. Budaya organisasi adalah hal yang dipersepsikan karyawan dan menciptakan suatu pola keyakinan, nilai, dan ekspektasi (Ivancevich, Konopaske, \& Matteson, 2007: 44). 
Budaya organisasi merupakan salah satu faktor penting dalam menentukan keberhasilan organisasi untuk mencapai tujuannya. OCB pada dosen berkembang seiring dengan proses sosialisasi nilai-nilai yang ada pada organisasi, ketika nilai-nilai yang dimiliki oleh organisasi memiliki "service value" maka OCB akan muncul pada dosen. Budaya organisasi merupakan pola asumsi dasar yang diciptakan, ditemukan, atau dikembangkan oleh kelompok tertentu saat belajar menghadapi masalah, adaptasi eksternal dan integrasi internal yang diajarkan kepada anggota sebagai cara yang benar untuk berpersepsi, berpikir, dan berperasaan sehubungan dengan masalah yang dihadapi (Schein dalam Ivancevich, Konopaske, \& Matteson, 2007:44; Schein, dalam Luthans, 2006: 124).

Demikian juga dengan perilaku dosen di UIN Suska Riau yang dipengaruhi oleh budaya organisasi. Perilaku dosen yang terlibat dengan organisasi dibentuk oleh etika organisasi, nilai-nilai, peraturan kerja dan struktur organisasi. Budaya organisasi membentuk dan mengendalikan perilaku dosen berkaitan dengan nilai profesi yang dianut, maka dosen diharapkan adaptif terhadap perubahan nilai budaya organisasi agar OCB pada dosen dapat menjadi lebih bermakna dan teraktualisasikan dalam melaksanakan tugas pekerjaannya. Seperti yang dikatakan oleh Priantoro (2008) tentang problem yang dihadapi oleh kebanyakan perguruan tinggi adalah bahwa dosen hanya diwajibkan dan dikontrol ketat pada aspek pengajaran semata, sedangkan pada aspek penelitian dan pengabdian pada masyarakat masih cenderung kurang diprioritaskan, padahal kemajuan institusi perguruan tinggi sangat ditentukan oleh keberadaan dosen yang berkualitas dengan kepemimpinan dosen yang memiliki kapabilitas memadai dalam kegiatan penelitian dan pengabdian pada masyarakat. Hal ini didukung juga oleh Robins dan Judge (2009); Mulyono dan Nasir (2006); Schein (1992) serta Kotter dan Haskett (1997) yang mengatakan bahwa faktor penentu perilaku kerja anggota organisasi antara lain adalah budaya organisasi dan kepemimpinan yang dijalankan pada organisasi tersebut.

Kepemimpinan yang baik diperlukan dosen berkaitan dengan tugas membimbing dan mengarahkan mahasiswa mencapai tujuan pengajaran dalam setiap mata kuliah yang diampunya, sesuai dengan kurikulum dan silabus sebagai acuan capaian yang telah ditetapkan pada setiap semester berjalan. Seperti yang dikatakan oleh Robbins (2004) bahwa kepemimpinan adalah kemampuan untuk mempengaruhi kelompok menuju pencapaian sasaran. Reddin (1996: 1) menyatakan pendapatnya mengenai kepemimpinan, bahwa setiap pemimpin memiliki gaya kepem- impinan yang berbeda dalam melaksanakan tugas kepemimpinan, ada tiga pola dasar yang dapat menentukan perilaku kepemimpinan, yaitu: berorientasi tugas (task oriented), berorientasi hubungan (relationship oriented) dan berorientasi hasil (effectiveness oriented).

Berdasarkan paparan uraian latar belakang masalah yang dihadapi dosen dalam melaksanakan tugas profesinya untuk memenuhi tri dharma perguruan tinggi maka perlu dilakukan penelitian untuk menganalisa apakah dimensi kepribadian (openness to experiences,conscientiousness, extraversion, agreeableness, neuroticism), budaya organisasi berpengaruh terhadap kepemimpinan dan apakah kepemimpinan berpengaruh terhadap OCB dosen UIN Suska Riau.

\section{Metode}

\section{Identifikasi Variabel}

Variabel bebas pada penelitian ini adalah: kepribadian, kepemimpinan, dan budaya organisasi. Kepribadian, yaitu kecenderungan dasar dosen untuk bereaksi sebagai interaksi faktor pribadi dan lingkungan yang diukur berdasarkanlima dimensi kepribadian big five yang meliputi: neuroticism, extraversion, openness to experience, agreebleness, conscientiousness (McCrae dalam Feist \& Feist, 2008: 363-365; Robbins, 2006: 13013; dan McCrae dalam Pervin, Cervone, \& John, 2004: 262-263; Ivancevich, Konopaske, \& Matteson, 2007: 95-96). Budaya organisasi yaitu pemahaman, keyakinan, kebiasaan dan cara berperilaku dosen sebagai cerminan sistem nilai yang membentuk anggota organisasi, struktur orgnanisasi dan sistem pengendalian organisasi yang menghasilkan norma - norma keyakinan sebagai modal psikologis untuk melakukan segala sesuatu di dalam organisasi dengan dimensi dan indikator aspek-aspek budaya organisasi dari Hofstede (2011) yaitu: process - Result Oriented, Employee - Job Oriented, Parochial - Profesional, Open - Closed System, Loose - Tight Control, Pragmatic - Normative.

Kepemimpinan yaitu: kemampuan dan kesiapan yang dimiliki oleh dosen untuk dapat mempengaruhi, mendorong, mengajak, menuntun, menggerakkan, dan melakukan upaya kepada individu mahasiswa atau kelompok agar menerima pengaruh tersebut dan selanjutnya membantu tercapainya suatu tujuan tertentu yang telah ditetapkan berdasarkan dimensi orientasi tugas, orientasi hubungan, dan orientasi hasil (Reddin, dalam LPSP3UI, 1996:1)

Variable terikat, yaitu Organizational Citizenship Behavior (OCB) OCB (organizational citizenship behavior). OCB (organizational citizenship behavior) merupakan per- 
ilaku dosen yang bersifat sukarela, bukan merupakan tindakan yang terpaksa terhadap hal-hal yang mengutamakan kepentingan organisasi, sebagai wujud dari kepuasan berdasarkan kinerja, bukan karena diperintah dengan cara formal, serta tidak berkaitan langsung dengan sistem reward yang formal dan memberikan manfaat bagi organisasi. OCB diukur dengan skala OCB yang dibuat peneliti. Dimensi OCB dalam skala OCB penelitian ini adalah helping behavior, sportmanship, organizational loyalty, organizational compliance, individual initiative, civic virtue dan self-development (Podsakoff, Mackenzie, Paine dan Bachrach, dalam Organ, Podsakoff \& Mackenzie, 2006: 297).

\section{Subjek}

Penelitian ini dilakukan pada 107 orang dosen Universitas Islam Negeri Sultan Syarif Kasim Riau (UIN SUSKA Riau). Subjek penelitian terdiri dari dosen laki - laki sebanyak 38 orang atau $36 \%$ dan dosen perempuan sebanyak 69 orang $(64 \%)$, dengan karakteristik sebanyak 7 orang $(6,54 \%)$ dosen berusia 26 - 30 tahun, 11 orang $(10,28 \%)$ dosen berusia $31-35$ tahun, 46 orang $(42,99$ $\%$ ) dosen berusia $36-40$ tahun, 23 orang $(21,50 \%)$ dosen berusia $41-45$ tahun, 14 orang $(13,08 \%)$ dosen berusia $46-50$ tahun, dan 6 orang $(5,61 \%)$ dosen berusia lebih dari 50 tahun. Berdasarkan penggolongan usia, dapat diketahui bahwa dosen pada umumnya berusia 36 - 40 tahun yang termasuk dalam masa usia produktif.

Berdasarkan masa kerjanya, responden penelitian terdiri dari 11 orang $(10,28$ $\%$ ) dosen dengan masa kerja $<5$ tahun, 35 orang $(32,71 \%)$ dosen dengan masa kerja 5 - 10 tahun, 34 orang $(31,78 \%)$ dosen dengan masa kerja 11 - 15 tahun, 15 orang $(14,02 \%)$ dosen dengan masa kerja 16 - 20 tahun, 6 orang $(5,61 \%)$ dosen dengan masa kerja 21 - 25 tahun, 5 orang $(4,67 \%)$ dosen dengan masa kerja 26 - 30 tahun, dan 1 orang $(0,93$ $\%)$ dosen dengan masa kerja lebih dari 30 tahun. Berdasarkan penggolongan masa kerja dosen, dapat diketahui bahwa dosen pada umumnya memiliki masa kerja 6-10 tahun di lingkungan UIN Suska Riau.

\section{Pengukuran}

Pada penelitian ini menggunakan empat skala dengan model Likert, yaitu skala OCB (Organizational Citizenship Behavior) terdiri dari 20 aitem, skala budaya organisasi terdiri 24 aitem, skala kepribadian terdiri dari 10 aitem dan skala kepemimpinan terdiri dari 7 aitem.Uji daya beda aitem data penelitian menunjukkan bahwa OCB (Organizational Citizenship Behavior) memiliki nilai koefisien korelasi aitem total pada skala OCB sebesar 0,258 sampai dengan 0,510 ; kepribadian me- miliki nilai koefisien korelasi aitem total pada skala Big Five Personality sebesar $-0,121$ sampai dengan 0,614 ; budaya organisasi memiliki dengan nilai koefisien korelasi aitem total pada skala Budaya Organisasi sebesar 0,224 sampai dengan 0,686, dan kepemimpinan memiliki nilai koefisien korelasi aitem total pada skala Kepemimpinan sebesar 0,263 sampai dengan 0,491. Nilai reliabilitas data penelitian menunjukkan bahwa organizationalcitizenship behavior memiliki nilai alpha cronbach sebesar 0,806, kepribadian memiliki nilai alpha cronbach 0,744 , budaya organisasi memiliki nilai alpha cronbach 0,901 , dan kepemimpinan memiliki nilai alpha cronbach 0,704 .

\section{Analsisi Data}

Uji hipotesis penelitian dilakukan dengan metode analisis regresi berganda, dan sederhana untuk mengetahui atau menjelaskan akibat langsung dari seperangkat variabel, variabel bebas terhadap variabel tergantung (Sitepu, 1994; 22).

\section{Hasil}

Uji normalitas dilakukan untuk mengetahui normal atau tidaknya persebaran data penelitian, dan mengetahui terpenuhi tidaknya syarat representatif data penelitian sehingga hasil penelitian dapat digeneralisasikan terhadap populasi. Hasil uji normalitas variabel Organizational Citizenship Behavior (OCB) dengan koefisien $\mathrm{K}-\mathrm{SZ}=0,961$; dan $p=0,314(p>0,05)$ menunjukkan bahwa sebaran data variabel Organizational Citizenship Behavior (OCB) adalah normal; hasil uji normalitas variabel kepemimpinan dengan nilai koefisien Ks-Z $=1,194$; dan $p=0,116$ ( $p>0,05$ ) menunjukkan sebaran data variabel Kepemimpinan adalah normal. Hasil uji normalitas variabel Budaya Organisasi menunjukkan nilai koefisien K-SZ $=0,507$; dan $\mathrm{p}=$ $0,959$ ( $p>0,05)$, nilai menunjukkan bahwa sebaran data variabel Budaya Organisasi adalah normal. Hasil uji normalitas variabel Kepribadian (Big Five Personality) dengan nilai koefisien K-SZ $=0,599$; dan $p=0,866$ ( $p>0,05$ ) menunjukkan bahwa sebaran data variabel Big Five Personality adalah normal.

Hasil uji linieritas masing - masing variabel bebas (prediktor) dan variabel tergantung (kriterium) menunjukkan uji linieritas antara Kepemimpinan dengan Organizational Citizenship Behavior (OCB) dengan nilai $F$ linearity sebesar 28,222 dengan signifikansi $p=0,000(p<0,05)$ yang berarti ada hubungan antara Kepemimpinan dan Organizational Citizenship Behavior (OCB) adalah linier. Hasil uji linieritas antaraBudaya Organisasi dengan Organizational Citizenship Behavior (OCB) dengan nilai $F$ linearity sebesar 48,834 
dengan signifikansi $p=0,000(p<0,05)$ menunjukkan bahwa hubungan antara Budaya Organisasi danOrganizational Citizenship Behavior (OCB) adalah linier. Hasil uji linieritas antara Kepribadian (big five personality) dengan Organizational Citizenship Behavior (OCB) dengan nilai $F$ linearity sebesar 69,285 dengan signifikansi $p=0,00(p<0,05)$ menunjukkan bahwa hubungan antara Kepribadian (big five personality) dan Organizational Citizenship Behavior (OCB) adalah linier.

Hasil uji multikolinearitas penelitian menunjukkan tidak ada nilai VIF diatas 10 atau tolerance di bawah 0,1 ; sehingga tidak ada gangguan hubungan variabel bebas terhadap variabel tergantung karena tidak ada korelasi yang tinggi antar variabel bebasnya.

Hasil uji hipotesis menunjukkan kepribadian berpengaruh positif dan sangat signifikan terhadap kepemimpinan (koefisien regresi $=0,420 ; p=0,000)$. Besaran pengaruh langsung kepribadian terhadap kepemimpinan adalah sebesar 0,632 atau dibulatkan menjadi $63,2 \%$. Dengan demikian, tinggi rendahnya atau baik buruknya kepemimpinan dipengaruhi oleh kepribadian sebesar $63,2 \%$, sedangkan sisanya $36,8 \%$ dijelaskan faktor lain. Budaya organisasi berpengaruh positif dan signifikan terhadap kepemimpinan dengan nilai koefisien regresi $=0,44, p=0,04$. Besaran pengaruh langsung budaya organisasi terhadap kepemimpinan adalah sebesar 0,199 atau dibulatkan menjadi $19,9 \%$. Artinya tinggi rendahnya atau baik buruknya kepemimpinan dipengaruhi oleh budaya organisasi sebesar $19,9 \%$ sedangkan sisanya $80,1 \%$ dijelaskan oleh faktor lain.

Kepemimpinan berpengaruh positif dan sangat signifikan terhadap organizational citizenship behavior dengan nilai koefisien $=$ 1,272 . Besaran pengaruh langsung kepemimpinan terhadap organizational citizenship behavior adalah sebesar 0,467 atau dibulatkan menjadi $46,7 \%$. Artinya tinggi rendahnya atau baik buruknya organizational citizenship behavior dipengaruhi oleh kepemimpinan sebesar $46,7 \%$ sedangkan sisanya 53,3\% dijelaskan oleh faktor lain.

\section{Pembahasan}

Dosen merupakan sumber daya yang sangat penting bagi perguruan tinggi, khususnya Universitas Islam Negeri Sultan Syarif Kasim Riau yang sedang berusaha menjadi salah satu perguruan tinggi kelas dunia yang terkemuka di Asia Tenggara, sebagaimana yang dituangkan dalam visi dan misi UIN Suska Riau 2020. Keberadaan dosen yang memiliki OCB atau perilaku kewarganegaraan organisasi diharapkan memberikan kontribusi lebih dari kewajiban formal untuk melaksanakan tri dharma perguruan tinggi dalam hal pendidikan dan pengajaran, penelitian, dan pengabdian masyarakat. Hal ini sesuai dengan pendapat Robbin (2006:34) dan Shekari (2013) bahwa perilaku pilihan yang tidak menjadi bagian dari kewajiban formal dapat mendukung fungsi organisasi secara efektif dan efisien. Penelitian ini membuktikan adanya pengaruh beberapa faktor yang dapat mempengaruhi tinggi rendah atau baik buruknya OCB dosen di perguruan tinggi yaitu dari sisi kepribadianan, budaya organisasi dan kepemimpinan.

Hasil penelitian ini membuktikan bahwa kepribadian berpengaruh positif dan sangat signifikan terhadap kepemimpinan. Kepribadian yang dikembangkan dan diterapkan oleh para dosen di UIN Suska Riau dapat mempengaruhi kegairahan aktivitas akademik dan non akademik sehingga dosen berusaha optimal mencapai tujuan perguruan tinggi dalam hal ini visi UIN Suska Riau. Dosen dapat menyesuaikan kepribadiannya dengan pola kepemimpinan yang tepat agar sesuai dengan situasi yang ada. Kepribadian sangat berguna bagi dosen dalam melaksanakan tugas profesi sehari-hari, karena dosen harus fokus pada tugas dan hasil yang dicapainya. Dosen memiliki kebebasan berkreativitas dalam menjalankan tugas tri dharma perguruan tinggi, artinya setiap dosen dapat menerapkan model kepribadiannya masing - masing sesuai dengan kepemimpinan masing -masing dosen. Hal ini didukung oleh teori dari Lewin (dalam Calvin \& Gardner, 2012) tentang medan fenomenal kognitif yang mempengaruhi tindakan individu, dimana orientasi kognitif dan afektif individu menentukan tindakannya dan berpengaruh pada perkembangan kepribadian individu, sehingga dapat difahami bahwa dimensi orientasi kepemimpinan individu dipengaruhi oleh kepribadiannya.

Hasil penelitian ini membuktikan bahwa budaya organisasi berpengaruh positif dan signifikan terhadap kepemimpinan. Dalam mengerjakan tugasnya sehari - hari, dosen juga harus mampu mengembangkan budaya organisasi yang baik dengan cara menjalin relasi yang baik dengan mahasiswa, karyawan civitas akademika dan rekan sejawat profesi dosen di lingkungannya. Dosen dapat melaksanakan tri dharma perguruan tinggi sesuai dengan budaya organisasi yang dikembangkannya di UIN Suska Riau sehingga diharapkan dapat berperan optimal sesuai orientasi kepemimpinannya masing - masing. Penelitian sebelumnya dari Naniek (2011) menunjukkan bahwa perilaku individu di lingkungan kerja dapat mempengaruhi kepemimpinan, jika hal ini dikaitkan dengan hasil penelitian ini maka dapat dikatakan bahwa perilaku dosen dengan pola keyakinan dan nilai-nilai yang dianut dalam aktifitas tugas sehari-hari di organ- 
isasi UIN Suska Riau berpengaruh terhadap kepemimpinan dosen. Hal ini didukung oleh teori dari Skinner (dalam Calvin \& Gardner, 2012) yang mengatakan bahwa prosespembentukan tingkah laku pada manusia umumnya bersifat alami, karena memang lingkungan berperan penting dalam pembentukan orientasi kepemimpinan seseorang, seperti alam sekitarnya, manusia-manusia yang tinggal berdekatan atau masyarakatsekitar (teman, rekan kerja, kondisi lingkungan dan peralatan kerja), dan gejala-gejala yang terjadi pada kehidupan sekitar baik positif maupun negatif, berpengaruh pada orientasi kepemimpinan seseorang.

Hasil penelitian ini menemukan adanya pengaruh langsung kepemimpinan terhadap OCB. Penelitian terdahulu yang dilakukan oleh Pramudyo (2010: 4) yaitu kepemimpinan mempunyai pengaruh signifikan terhadap kinerja dosen dan menurut Milwati (2012: 321), kinerja dosen dapat ditingkatkan secara langsung melalui OCB dan secara tidak langsung kepemimpinan berpengaruh positif terhadap OCB yaitu OCB dosen akan semakin menguat apabila pemberdayaan dosen dan komitmen organisasional dosen semakin meningkat.

Kemudian penelitian dari Brown dan Trevino (dalam Kalshoven, Den Hartog, \& De Hoogh, 2011) menemukan bahwa adahubungan antara kepemimpinan dengan kepribadian, dalam hal ini trait Big Five yaitu conscientiousness, agreeableness, dan neuroticism. Selain ituMayer (dalam Kalshoven, Den Hartog, \& De Hoogh, 2011) juga menemukan bahwa kepemimpinan berhubungan dengan agreeableness, conscientiousness, dan neuroticism. Hal ini menunjukkan bahwa kepemimpinan pada diri individu tumbuh dan berkembang karena adanya pengaruh karekteristik personal individu yaitu kepribadian (Nall\& Aull, 2011). Sehingga dengan melihat hasil penelitian ini, maka kepemimpinan dosen di UIN Suska Riau yang diperkuat oleh kepribadian dan budaya organisasi dapat berpengaruh terhadap timbulnya OCB dosen, dan OCB dosen merupakan salah satu faktor penting yang dapat berperan mencapai tujuan perguruan tinggi.

\section{Kesimpulan}

Berdasarkan hasil dan pembahasan dapat diambil kesimpulan, pertama ada pengaruh yang signifikan antara kepribadian terhadap kepemimpinan. Aspek kognitif dan afektif yang terbentuk oleh faktor bawaan dan lingkungan merupakan bagian dari faktor pembentuk kepribadian dosen, kepribadian ini yang kemudian mempengaruhi tindakan individu, dimana orientasi kognitif dan afektif individu dapat menentukan tindakannya dan berpengaruh pada perkembangan kepem- impinan dosen dalam melakukan tugas sehari-hari melaksanakan tri dharma perguruan tinggi di UIN Suska Riau, sehingga dapat difahami bahwa dimensi orientasi kepemimpinan individu dipengaruhi oleh kepribadiannya.

Kedua, ada pengaruh yang signifikan antara budaya organisasi terhadap kepemimpinan. Dalam hal ini, sistem nilai yang terbentuk di organisasi UIN Suska Riau menjadi suatu keyakinan bersama yang dianggap baik untuk dilakukan dalam melaksanakan aktivitas tugas pekerjaan sehari-hari. Sistem nilai tersebut berpengaruh terhadap proses pembentukan pola perilaku kepemimpinan dosen. Karena hampir setiap hari dosen berinteraksi dengan penyesuaian diri agar berperilaku sama dan ciri - ciri khas yang berkembang seiring dengan proses sosialisasi nilai-nilai yang ada pada organisasi, ketika nilai-nilai yang dimiliki oleh organisasi memiliki "service value" maka lingkungan dapat berpengaruh pada perkembangan kepemimpinan dosen di UIN Suska Riau. Ketiga, ada pengaruh yang sangat signifikan antara kepemimpinan terhadap Organizational Citizenship Behavior pada dosen tetap UIN Suska Riau. Kepemimpinan memiliki pengaruh yang besar terhadap OCB. Dosen dengan kepemimpinan yang baik memiliki kualitas perhatian yang baik terhadap hubungan interpersonal, ia lebih mengutamakan hubungan yang harmonis dengan orang lain, ia mampu dengan baik membina hubungan kerja sama dengan atasannya, dengan koleganya yang setingkat dan terutama dengan bawahannya atau mahasiswanya, sehingga dapat difahami bahwa dosen dengan kepemimpinan yang mengutamakan relationship oriented memiliki OCB yang baik atau tinggi dalam menjalankan aktivitas tugas sehari-hari. Adanya OCB yang baik pada dosen UIN Suska dapat diharapkan akan tercapainya visi dan misi organisasi UIN Suska Riau.

\section{Daftar Pustaka}

Azwar, S. (2013 a). Metode Penelitian. Yogyakarta: Pustaka Pelajar.

(2013 b). Penyusunan Skala Psikologi. Yogyakarta: Pustaka Pelajar. (2009). Reliabilitas dan Validitas. Yogyakarta: Pustaka Pelajar.

Bass, B. M. (1990). Bass and Stogdill's handbook of leadership (3rd ed.). New York: Free Press.

Caroselli, Marcelene. (2000). Leadership Skill for Managers, New York: McGraw-Hill.

Calvin S. Hall \& Gardner Lindzey. (2012). Teori - teori Sifat dan Behavoiristik, Seri Psikologi Kepribadian 3. Yogyakarta: Kanisius

Daff, Richard L.(2005). The Leadership Experience Canada: Thomson.

Dana, M. H.(2007). Hubungan Kepuasan Ker- 
ja dan Komitmen Organisasi dengan Organizational Citizenship Behavior Di Poltek Kesehatan Banjarmasin. Working Paper Series. No. 2 Januari 2007.

Darsana, M. (2013). The Influence Of Personality And Organizational Culture On Employee Performance Through Organizational Citizenship Behavior. The International Journal Of Management. Vo 2, Issue 4. Oktober. $35-42$.

Debora E.P., \& Ali NLS. (2004). Pengaruh Kepribadian Dan Komitmen Organisasi Terhadap Organizational Citizenship Behavior. JurnaL Makara, Sosial Humaniora.vol. 8. Nomor 3. 105 - 111. Depok: Universitas Indonesia.

Darmawati, A., Hidayati, L. N., \& Herlina, D. S. Tanpa Tahun. Pengaruh Kepuasan Kerja dan Komitmen Organisasi Terhadap Organizational Citizenship Behavior. Studi Pada Karyawan Fakultas IImu Sosial Dan Ekonomi Universitas Negeri Yogyakarta. Laporan Penelitian. Yogayakarta: Fakultas IImu Sosial Dan Ekonomi Universitas Negeri Yogyakarta.

Ebrahimpour, H., Zahed, A., Khaleghkhah, A., \& Sepehri, M.B. (2011). A Survey Relation Between Organizational Culture and Organizational Citizenship Behavior. Procedia-Social and Behavioral Sciences. Volume 30, 1920 - 1925.

Elfina, P D. (2003). Pengaruh Konflik dan Komitmen Organisasi terhadap Perilaku Citizenship Karyawan. Jurnal Sosial Humaniora. Vol. 7, nomor 2. 99- 107. Depok: Universitas Indonesia.

Farvoodi, J. A., K., Enayati, G., \& Malekzadeh, G. (2013). Investigation of Feist, J., Feist, G. (2008). Theories of Personality, (Edisi Keenam). Alih Bahasa: Yudi Santoso. Yogyakarta: Pustaka Pelajar.

Griffin, Ricky. (2000). Management, Edisi 2, Erlangga, Jakarta.

Relationship Style of Consultative, Leadership Style of Participative Citizenship Behavior A Case Study of Ahromsazeh Mashhad Company. International Journal Of Advanced Studies in Humanitie and Social Science. Vol. 1, Issue 6. 665 - 669.

Feist, J., \& Feist, G.J. (2008). Theories of Personality. Alih Bahasa: Yudi Santoso. Yogyakarta: Pustaka Pelajar.

Fitriyani, W. (2013). Pengaruh Kepribadian dan Job Embedness Terhadap Organizational Citizenship
Behavior (OCB) Pada Karyawan PT. Hadji Kalla Makassar. Skripsi. Makasar: Jurusan Manajemen, Fakultas Ekonomi dan Bisnis Universitas Hasanuddin.

Hadi, S. (2004). Metodologi research. Jilid 2. Yogyakarta: Penerbit Andi Offset.

Hardaningtyas.(2004). Pengaruh Tingkat Kecerdasan Emosi dan Sikap Pada Budaya Organisasi Terhadap Organizational Citizenship Behavior (OCB). Tesis. Surabaya: Universitas Air Langga.

Hartono. (2012). Statistik Untuk Penelitian. Yogyakarta: Pustaka Pelajar bekerjasama dengan Zanafa Publishing.

Hee Lee, U., Kyoung Kim, H., \& Hyung Kim, Y. (2013). Determinants of Organizational Citizenship Behavior and Its Outcomes. Global Business and Management Research: An International Journal. Vol 5, No. 1, $54-65$.

Hofstede, G. 2011. Dimensionalizing Cultures: The Hofstede Model in Context. Online Readings in Psychology and Culture, 2 (1). Diakses dari: http: //dx.doi. org/10.9707/2307-0919.1014. akses tanggal: 20 April 2014.

Ilyasssin, M. (2010). Budaya organisasi bagi peningkatan kinerja dosen.Laporan Penelitian. Samarinda: STAIN

Iskandar, D. (2011). Dosen Malas. Artikel. Diakses dari: http:// gemasastrin. wordpress.com/2011/10/05/dosen malas/. Diakses tgl 23 Januari 2014.

Ivancevich, J.M., Konopaske, R., \& Matteson, M. T. (2007). Perilaku dan Manajemen Organisasi. Alih Bahasa: Gina Gania. Jakarta: Erlangga.

Jayanti, R. (2009). Perbedaan Organizaional Citizenship Behavior Antara Pegawai dengan Tipe Kepribadian Ekstrovert dan Introvert. Skripsi. Medan: Fakultas Psikologi Unuversitas Sumatera Utara.

Kalshoven, K., Den Hartog, D., \& De Hoogh, A.H.B. (2011). Ethical Leader Behavior and Big Five Factors of Personality. Journal of Business Ethics.

Kotter, John P. \& Heskett, James L. (1997). Corporate Culture \& Performance (Benyamin Molan, Penerjemah). Jakarta: Prenhallindo.

Lee, U. H., Kyoung Kim, H., \& Hyung Kim, Y. (2013). Determinants of Organizational Citizenship Behavior and Its Outcomes. Global Business and Management Research: An International Journal. Vol 5, 
Luthans, F. (2006). Perilaku Organisasi. Alih Bahasa: Vivik A.Y., Shekar, P., Arie P., \& Winong, R. Yogyakarta: Penerbit Andi. LPSP3UI. (1996). Alat Ukur Gaya Kepemimpinan - MSDT. Jakarta. Fakultas Psikologi, Universitas Indonesia.

MacKenzie, S. B., Podsakoff, P. M., \& Ahearne, M. (1998). Some possible antecedents and consequences of in-role and extra-role salesperson performance. Journal of Marketing, 62: 87-98.

Mahendra, R. (2009). Pengaruh Kepuasan Kerja, Komitmen Organisasi dan Lingkungan Kerja terhadap Organizational Citizenship Behavior (OCB) Pegawai Bagian Umum Kantor Sekretariat Daerah Kabupaten. Skripsi. Semarang: Fakultas Ekonomi Universitas Negeri Semarang. Diunduh dari www.fe.unnes.ac.id

Mangundjaja, W. H. 2010. Pengaruh Komitmen Organisasi Pada Perilaku Kewarganegaraan Organisasi (Studi Komparatif Pada Perusahaan Yang Bergerak Dalam Bidang Keuangan dan Minyak Serta Gas Bumi). Proceedings. Jakarta: Temu Ilmiah Psikologi.

Martono, N. 2012. Metode Penelitian Kuantitatif. Analisis Isi dan Analisis Data Sekunder. Jakarta: PT Raja Grafindo Perkasa.

Milwati, Susi. 2012. Hubungan antara kepemimpinan, komitmen organisasional, organizational citizenship behavior dan pemberdayaan dengan kinerja dosen Pliteknik Kesehatan Ke menterian Kesehatan di Jawa Timur. Disertasi (tidak diterbitkan). Malang: Universitas Negeri Malang.

Mohanty, J., \& Rath, B. P. (2012a). Can Organizational Cultur Be A Predictor Of Organizational Citizenship Behaviors? International Journal Of Innovation, Management and technology. Volume. 3, No. 1. 76 - 79.

Mohanty, J., \& Rath, B.P. (2012b). Influence of Organizational Culture on Organizational Citizenship Behavior: A Three - Sector Study. Global Journal of Business Research, Volume 6, No. 1, $65-76$.

Mulyono. S dan Nasir. A. (2012). Memetakan Budaya Organisasi Atas Dasar Gaya Kepemimpinan dan Pengaruhnya Terhadap Kinerja Dosen. Journal. Volume 11, Nomor 2, September. 194 - 216. Fakultas Ekonomi dan Bisnis, Universitas Gajayana. Malang.
Nall, M. \& Aull, M. 2011. The Influence of Personal Characteristics. Personality, Culture, and Environment. UKAg Extension, Kentucky Extension Leadership Development.

Naniek Risnawati. 2011. Kepribadian Sekretaris Yang kompeten. Jurnal: STIE Semarang. Vol. 3, No. 3. 31 41.

Organ, D.W, Podsakof, P.M and Ma cKe nzi e, S.B. ( $\left.\begin{array}{llll}2 & 0 & 0 & 6\end{array}\right)$. Organizational Citizenship Behavior: Its Nature, Antecedents and Consequences. United States of America: Sage Publications, Inc.

Organ, D. W and Ryan, K. 1995. A MetaAnalytic Review of Attitudinal and Dispositional Predictors of Organizational Citizenship Behavior. Person. el Psychology. School of Business, Indiana University.

Pervin, L.A., Cervone, D., \& John, O. P. (2004). Psikologi Kepribadian: Teori dan Penelitian. Edisi kesembilan. Alih Bahasa: A.K. Anwar. Jakarta: Kencana Prenada Media Gorup.

Podsakoff, P. M., Ahearne, M., \& Mankenzie, S. B. (1997). Organizational Citizenship Behavior and The Quantity and Quality of Work Group Performance. Journal of Applied Psychology. Vol. 82. No. 2, $262-270$. Podsakoff, P.M., Mazkenzie, S.B., Paine, J. B., \& Bachrach, D. G. (2000). Organizational Citizenship Behaviors: A Critical Review of The Theoretical and Empirical Literature and Suggestions for Future Research. Journal of Management. Vol. 26, No. $3,513-563$.

PP Nomor: 66 Tahun (2010). Tentang Perubahan Atas Peraturan Pemerintah Nomor 17 Tahun 2010 Tentang Pengelolaan dan Penyelenggaraan Pendidikan. Pemerintah Republik Indonesia.

Pramudyo, A. (2010). Analisis Faktor-Faktor yang Mempengaruhi Kinerja Dosen Negeri Dipekerjakan Pada Kopertis Wilayah $V$ Yogyakarta. Jurnal BTI AMA "YPN". Vol.1, No.1, 1 - 11.

Pratiwi, I. (2013). Analisis Pengaruh Budaya Organisasi dan Keadilan Organisasi Terhadap Organizational Citizenship Behavior (OCB) dengan Komitmen Organisasional Sebagai variabel Intervening (Studi Pada Karyawan Kantor PT Telekomunikasi Indonesia Tbk. Divisi Regional IV Wilayah Jateng dan DIY). Skripsi. Semarang: Fakultas Ergonomika dan Bisnis, Universitas Diponegoro. 
Rahmi, B.M. (2013). Pengaruh Kepemimpinan Transformasional Terhadap Organizational Citizenship Behavior dan Komitmen Organisasional Dengan Mediasi Kepuasan Kerja (Studi Pada Guru Tetap SMA Negeri 1 di Kabupaten Lombok Timur). Tesis. Denpasar: Program Pascasarjana Universitas Udayana.

Reddin. (1996). Management Style Diagnostic Test (MSDT). Jakarta. Fakultas Psikologi, Universitas Indonesia.

Robbins, S. P. 2006. Perilaku Organisasi. Alih Bahasa: Benyamin Molan. Jakarta: PT Macnaan Jaya Cemerlang.

Robbins, S.P. 2002. Perilaku Organisasi. Konsep, Kontroversi, dan Aplikasi. Jakarta: PT Prenhallindo.

Robbins. 2004. Budaya Korporat dan Keunggulan Korporasi. Jakarta: PT. Elex Media Komputindo

Robbins, Stephen P. dan Judge, Timothy A., 2009. Organizational Behavior. 13th Edition. Pearson Education, Inc., Upper Saddle River, New Jersey.

Sahertian, P. (2010). Perilaku Kepemimpinan Berorientasi Hubungan dan Tugas Sebagai Anteseden Komitmen Organisasi. Jurnal Manajemen Kewirausahaan. Vol.12, No.2: 156169.

Sari, K. M., \& Hajriani, E. (2015). Pengauh Karakteristik Budaya Organisasi terhadap Organizational Citizenship Behavior. Journal of Economic and Economic Education, Volume 3. Nomor 2 (228 - 236). Padang: Prodi Pendidikan Ekonomi STKIP PGRI Padang.

Schein, Edgar H. 2004. Organizational culture and leadership. 3rd ed. Published by Jossey-Bass. San Francisco

Shekari,H. (2013). Promoting Organizational Citizenship in Organizations: A Reflection on Servant Leadership Approach. International Journal Of Management and Humanity Sciences. Vol. 2 (8), 787-800).

Sitepu, N. SK. (1994), Analisis Regresi, Unit Pelayanan Statitika Jurusan Statistika, Bandung : FMIPA UNPAD.

Somech, A. \& Zahavy, A.D. (2004). Exploring Organizational Citizenship Behaviour From An Organizational Perspective: The Relationship Between Organizational Learning And
OrganizationaL Citizenship Behavior. Journal of Occupational and Organizational Psychology. No. 77, pp. 281-298.

Stefhani. (2014). Analisis Pengaruh Stres Kerja dan Organizational Citizenship Behavior Terhadap Kepuasan Kerja dan Dampaknya Terhadap Retensi Karyawan Di Ford Jakarta Pusat. Binus Business Review. Vol. 5 No. 1 Mei 2014: 39-48. Management Department, School of Business Management, BINUS University. Jakarta Barat.

Suhardan, D. (2010). Supervisi Profesional layanan meningkatkan Mutu Pembelajaran di Era Otonomi Daerah. Alfabeta: Bandung.

Tampubolon, D. P. (2001). Perguruan Tinggi Bermutu Paradigma Baru Manajemen Pendidikan Tinggi Menghadapi Tantangan Abad ke-21. PT Gramedia Pustaka Utama. Jakarta.

Thoyib. A. 2005. Hubungan Kepemimpinan, Budaya, Strategi, dan Kinerja: Pendekatan Konsep. Jurnal. Staf Pengajar Fakultas Ekonomi Universitas Brawijaya Malang.

Triandis, H.C., \& Eunkook, M.S. (2002). Cultural Influences on Personality. Annu Rev Psychology. 53: 133-160.

Undang - Undang Nomor 14 tahun (2005). Tentang guru dan dosen. Diakses dari: http://kutacane-online.blogspot. Com /2011/11/pengertian-guru-dosendan-guru-besar.html. Diakses tanggal 20 April 2014.

Widhiarso. W. Menghitung Sumbangan Efektif Tiap Aspek terhadap Variabel Dependen. Diakses dari: http:/www. google.co.id/url?=t\&rct=j \&q-mencari +sumbangan+efektif/per $=+$ aspek+tiap+variabel+bebas\&saurc $\mathrm{e}=$ web\&cd=1\&ved=OahUKEwi6tdCH ONPKAhWHGY4KHfBKCxMQFgga AA\&url=http $\% 3 A \% 2 F \% 2 F$ widhiarso. Staff.ugm.ac.id\%2Ffiles\%2Fmencari $\% 2520$ Sumbangan $\% 2520$ Efektif $\% 25$ 20Aspek\%2520Fariabel.pdf, diakses tanggal 13 Januari 2016.

Widhiastuti. H. (2014). Big Five Personality sebagai Prediktor Kreativitas dalam Meningkatkan Kinerja Anggota Dewan. Jurnal. Vol. 41, No. 1, JUNI 2014: 115 - 133 . Fakultas Psikologi Universitas Semarang. Semarang. 